\title{
Macrophage migration inhibitory factor - a therapeutic target in gallbladder cancer
}

Tejaswini Subbannayya ${ }^{1,2 \dagger}$, Pamela Leal-Rojas ${ }^{3,4+}$, Mustafa A. Barbhuiya ${ }^{4,5}$, Remya Raja ${ }^{1}$, Santosh Renuse ${ }^{1,2}$, Gajanan Sathe ${ }^{1,6}$, Sneha M. Pinto ${ }^{1,7}$, Nazia Syed ${ }^{1,8}$, Vishalakshi Nanjappa ${ }^{1,2}$, Arun H. Pati ${ }^{1,9}$, Patricia Garcia ${ }^{10}$, Nandini A. Sahasrabuddhe ${ }^{1}$, Bipin Nair ${ }^{2}$, Rafael Guerrero-Preston ${ }^{11}$, Sanjay Navani ${ }^{12}$, Pramod K. Tiwari ${ }^{13,14}$, Vani Santosh ${ }^{15}$, David Sidransky ${ }^{11}$, T. S. Keshava Prasad ${ }^{1,2,7,16}$, Harsha Gowda ${ }^{1,7}$, Juan Carlos Roa ${ }^{10}$, Akhilesh Pandey $4,17,18,19$ and Aditi Chatterjee ${ }^{1,6,7^{*}}$

\begin{abstract}
Background: Poor prognosis in gallbladder cancer is due to late presentation of the disease, lack of reliable biomarkers for early diagnosis and limited targeted therapies. Early diagnostic markers and novel therapeutic targets can significantly improve clinical management of gallbladder cancer.

Methods: Proteomic analysis of four gallbladder cancer cell lines based on the invasive property (non-invasive to highly invasive) was carried out using the isobaric tags for relative and absolute quantitation labeling-based quantitative proteomic approach. The expression of macrophage migration inhibitory factor was analysed in gallbladder adenocarcinoma tissues using immunohistochemistry. In vitro cellular assays were carried out in a panel of gallbladder cancer cell lines using MIF inhibitors, ISO-1 and 4-IPP or its specific siRNA.
\end{abstract}

Results: The quantitative proteomic experiment led to the identification of 3,653 proteins, among which 654 were found to be overexpressed and 387 were downregulated in the invasive cell lines (OCUG-1, NOZ and GB-d1) compared to the non-invasive cell line, TGBC24TKB. Among these, macrophage migration inhibitory factor (MIF) was observed to be highly overexpressed in two of the invasive cell lines. MIF is a pleiotropic proinflammatory cytokine that plays a causative role in multiple diseases, including cancer. MIF has been reported to play a central role in tumor cell proliferation and invasion in several cancers. Immunohistochemical labeling of tumor tissue microarrays for MIF expression revealed that it was overexpressed in 21 of 29 gallbladder adenocarcinoma cases. Silencing/inhibition of MIF using siRNA and/or MIF antagonists resulted in a significant decrease in cell viability, colony forming ability and invasive property of the gallbladder cancer cells.

Conclusions: Our findings support the role of MIF in tumor aggressiveness and suggest its potential application as a therapeutic target for gallbladder cancer.

Keywords: Gastrointestinal cancer, RNA interference, Functional inhibition, Suicide substrate, MIF

\section{Background}

Gallbladder cancer (GBC) is a prevalent malignancy of the biliary tract and is the fifth common cancer of the gastrointestinal tract worldwide [1]. In majority of the cases, it manifests at an advanced and unresectable stage

\footnotetext{
*Correspondence: aditi@ibioinformatics.org

${ }^{\dagger}$ Equal contributors

'Institute of Bioinformatics, International Technology Park, Bangalore 560066, India

${ }^{6}$ Manipal University, Madhav Nagar, Manipal 576104, India

Full list of author information is available at the end of the article
}

$[1,2]$. Early detection is incidental, with complete surgical resection of the gallbladder being the only available curative option. The prognosis is dismal with a five-year survival rate of $32 \%$ for lesions confined to the gallbladder mucosa and a one year survival rate of $10 \%$ for advanced stages [2]. To date, various markers including carbohydrate antigen 19-9 (CA19-9) and carcinoembryonic antigen (CEA) have been explored in the diagnosis of GBC. However, these markers lack specificity and sensitivity [3]. Targeted therapy for GBC is limited with bevacizumab which is a vascular endothelial growth

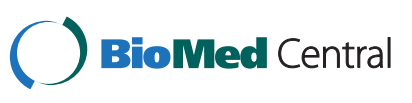

(C) 2015 Subbannayya et al. Open Access This article is distributed under the terms of the Creative Commons Attribution 4.0 International License (http://creativecommons.org/licenses/by/4.0/), which permits unrestricted use, distribution, and reproduction in any medium, provided you give appropriate credit to the original author(s) and the source, provide a link to the Creative Commons license, and indicate if changes were made. The Creative Commons Public Domain Dedication waiver (http://creativecommons.org/publicdomain/zero/1.0/) applies to the data made available in this article, unless otherwise stated. 
factor (VEGF) inhibitor [4]. Apart from bevacizumab, potential therapeutic targets such as estrogen receptor [5], hedgehog signaling [6] and mTOR inhibitors [7] are pending clinical validation. This highlights an immediate need for identification of novel therapeutic targets to improve treatment options and disease outcome.

Mass spectrometry-based proteomic analysis in tandem with isobaric tags for relative and absolute quantitation (iTRAQ) labeling has been employed for the identification of potential biomarkers in several cancers. We have used similar approaches in the past to identify potential biomarkers in esophageal squamous cell carcinoma [8], hepatocellular carcinoma [9] and head and neck squamous cell carcinoma [10]. Similar proteomic strategies have been employed by other groups to identify potential biomarkers in GBC using bile, serum and cell line-based models [11-14]. However, limited effort has been made to identify potential therapeutic targets in GBC. In this study, we used high-resolution mass spectrometry coupled with iTRAQ-based labeling approach to identify proteins which can serve as potential diagnostic markers and/or therapeutic targets. Using a panel of GBC cell lines, we identified a total of 3,653 proteins of which 654 were found to be overexpressed and 387 were downregulated in invasive GBC cell lines as compared to the non-invasive GBC cell line. Amongst these, macrophage migration inhibitory factor (MIF) was found to be overexpressed in two of the invasive GBC cell lines.

MIF is a pro-inflammatory cytokine which plays a key role in innate and adaptive immunity and is associated with inflammatory conditions including cancer. It is secreted by a variety of cells including immune and epithelial cells [15]. MIF has been reported to be overexpressed in multiple cancers, including gastric adenocarcinoma [16], head and neck squamous cell carcinoma [17], esophageal squamous cell carcinoma [18], colorectal [19], pancreatic [20], ovarian [21], and prostate [22] cancers. Knockdown of MIF in a murine ovarian cancer cell line, ID8 has been shown to decrease tumor growth and increase the survival in tumor transplanted mice [21]. Similar results were demonstrated in mice grafted with colorectal carcinoma transplants, administered with antiMIF therapeutics, using either MIF-antibodies or the MIF antagonist (S, R)-3-(4-hydroxyphenyl)-4,5-dihydro-5-isoxazole acetic acid methyl ester (ISO-1) [19]. Pharmacological inhibition of MIF using the MIF irreversible inhibitor, 4-iodo-6-phenylpyrimidine (4-IPP) has shown a decrease in tumor aggressiveness in head and neck squamous cell carcinomas [17] and lung adenocarcinomas [23]. The role of MIF in tumorigenesis has been characterized in other cancers however its function in $\mathrm{GBC}$ is yet to be established. In this study, we have assessed the role of MIF as a potential therapeutic target in GBC.

\section{Methods}

\section{Cell culture}

The GBC cell lines, OCUG-1 and NOZ were obtained from Health Science Research Resources Bank, Osaka, Japan. TGBC2TKB, TGBC24TKB and G-415 were purchased from RIKEN Bio Resource Center, Ibaraki, Japan. SNU-308 was obtained from Korean Cell Line Bank, Seoul, Korea. GB-d1 was authenticated by short tandem repeat analysis. The properties and culture conditions of the GBC cell lines, TGBC2TKB, SNU-308, G-415, TGBC24TKB, NOZ, OCUG-1 and GB-d1 are provided in Additional file 1. All cell lines were maintained in humidified incubator with $5 \% \mathrm{CO}_{2}$ at $37{ }^{\circ} \mathrm{C}$.

\section{Protein extraction and iTRAQ labeling}

Each cell line was grown to $\sim 80 \%$ confluence, serum starved for $8 \mathrm{~h}$ and lysed in $0.5 \%$ SDS-containing buffer. Protein concentration was measured using the BCA method [24]. Equal amount of protein from each cell line was then split into two and treated as technical replicates. Peptides from each sample were differentially labeled using iTRAQ 8-plex reagent (iTRAQ Reagents Multiplex kit, Applied Biosystems/MDS Sciex, Foster City, CA) as described earlier [25]. Briefly, $100 \mu \mathrm{g}$ of proteins, in replicate, was treated with $2 \mu \mathrm{l}$ of reducing agent (TCEP, tris (2-carboxyethyl) phosphine) at $60{ }^{\circ} \mathrm{C}$ for $1 \mathrm{~h}$ and alkylated with $1 \mu \mathrm{l}$ of cysteine blocking reagent, MMTS (methyl methanethiosulfate) for $10 \mathrm{~min}$ at room temperature. Protein samples were digested using sequencing grade trypsin (Promega, San Luis Obispo, $\mathrm{CA})$ at a $1: 20$ enzyme to protein ratio for $12 \mathrm{~h}$ at $37^{\circ} \mathrm{C}$. Peptides from each cell line were labeled with 8 iTRAQ reagents in $60 \mu \mathrm{l}$ of isopropanol at room temperature as follows - TGBC24TKB (reporter ion $\mathrm{m} / \mathrm{z} 113$ and 114), OCUG-1 (reporter ion $\mathrm{m} / \mathrm{z} 115$ and 116), NOZ (reporter ion $\mathrm{m} / \mathrm{z} 117$ and 118) and GB-d1 (reporter ion $\mathrm{m} / \mathrm{z} 119$ and 121). After $2 \mathrm{~h}$, the reaction was quenched by adding $100 \mu \mathrm{l}$ of water to each sample. The samples were then pooled and vacuum dried.

\section{Strong cation exchange chromatography}

The iTRAQ labeled peptides were fractionated using strong cation exchange chromatography as previously described [8]. Briefly, the pooled iTRAQ-labeled sample was reconstituted with solvent A $\left(10 \mathrm{mM} \mathrm{KH}_{2} \mathrm{PO}_{4}, 25 \%\right.$ acetonitrile, $\mathrm{pH} 2.8$ ). The $\mathrm{pH}$ of the sample was adjusted to 2.8 using ortho-phosphoric acid. The peptides were loaded onto a PolySULFOETHYL A column (PolyLC, Columbia, MD) $(5 \mu \mathrm{m}, 200 \AA, 200 \times 2.1 \mathrm{~mm})$ using Agilent 1260 Infinity series binary HPLC system (Agilent Technologies, Santa Clara, CA). Peptides were loaded at a flow rate of $250 \mu \mathrm{l} / \mathrm{min}$ and washed for $8 \mathrm{~min}$ with solvent A. A 35 min gradient from $0 \%$ to $60 \%$ solvent $\mathrm{B}$ (350 $\mathrm{mM} \mathrm{KCl}$ in solvent $\mathrm{A}, \mathrm{pH} \mathrm{2.8)}$ was used for 
fractionation. The peptides were detected at a wavelength of $214 \mathrm{~nm}$ using a variant wavelength detector module of HPLC system. A total of 96 fractions were collected and further pooled into 24 fractions based on chromatographic peaks. The pooled fractions were vacuum dried and desalted using $\mathrm{C}_{18}$ StageTips and stored at $-20{ }^{\circ} \mathrm{C}$ till further analysis.

\section{LC-MS/MS analysis}

Peptide fractions were analyzed on an LTQ-Orbitrap Velos mass spectrometer (Thermo Scientific, Bremen, Germany) interfaced with Proxeon Easy nLC II system (Thermo Scientific, Bremen, Germany). Peptides were loaded onto trap column $(75 \mu \mathrm{m} \times 2 \mathrm{~cm}$, Magic C18AQ, $5 \mu \mathrm{m}, 100 \AA$, Michrom Biosciences Inc., Auburn, CA) using solvent A $(0.1 \%$ formic acid) at a flow rate of $3 \mu \mathrm{l} / \mathrm{min}$ and resolved on an analytical column $(75 \mu \mathrm{m} \times 10 \mathrm{~cm}$, Magic C18AQ, $3 \mu \mathrm{m}, 100 \AA$, Michrom Biosciences Inc, Auburn, CA) at a flow rate of $350 \mathrm{nl} / \mathrm{min}$ using a linear gradient of $7-30 \%$ acetonitrile over $80 \mathrm{~min}$. The MS and MS/MS scans were acquired at a mass resolution of 60,000 and 15,000 at $400 \mathrm{~m} / \mathrm{z}$, respectively. Full MS scans were acquired in m/z range of $350-1800$. For each cycle, twenty most abundant precursor ions with charge state $\geq 2$ were sequentially isolated. The fragmentation was carried out using higher energy collision dissociation as the activation method with $40 \%$ normalized collision energy. Isolation width was set to $2 \mathrm{~m} / \mathrm{z}$. Singly charged precursor ions and precursors with unassigned charge states were rejected. The acquired ions were dynamically excluded for $45 \mathrm{~s}$. The automatic gain control for full MS and MS/MS was set to $1 \times 10^{6}$ and $5 \times 10^{4}$ ions, respectively. The maximum ion accumulation time was set to $100 \mathrm{~ms}$ for MS and $300 \mathrm{~ms}$ for MS/MS scans. The lock mass option was enabled using polysiloxane ion $(\mathrm{m} / \mathrm{z}, 445.120025)$ from ambient air for internal calibration as described [26].

\section{Data analysis}

The raw data obtained was processed using Proteome Discoverer (version 1.4) software suite (Thermo Fisher Scientific, Bremen, Germany) and searched using Sequest and Mascot (version 2.2.0, Matrix Science, London, UK) search algorithms against human protein database NCBI RefSeq (Release 63 containing 71,434 protein sequences and known contaminants). The search parameters included: trypsin as the proteolytic enzyme with two missed cleavages allowed, oxidation at methionine as the dynamic modification, alkylation (methylthio) at cysteine and iTRAQ 8-plex modification at $\mathrm{N}$-terminus of the peptide and lysine as static modifications. Precursor and fragment mass tolerance were set to $20 \mathrm{ppm}$ and $0.05 \mathrm{Da}$, respectively. The peptide and protein data were extracted using high peptide confidence and top one peptide rank filters. The data were also searched against a decoy database to calculate the false discovery rate (FDR). Peptide spectrum matches (PSMs) at $1 \%$ FDR were used for protein identifications. iTRAQ quantitation was done by taking the average of the reporter ion intensities from the technical replicates. The ratios, invasive neoplastic/ non-invasive neoplastic, were obtained as follows $115+116$ (OCUG-1)/113 + 114 (TGBC24TKB), $117+$ $118(\mathrm{NOZ}) / 113+114 \quad(\mathrm{TGBC} 24 \mathrm{TKB})$ and $191+121$ (GB-d1)/113 + 114 (TGBC24TKB).

\section{Bioinformatics analysis}

Proteins identified in this study were classified based on their subcellular localization, molecular function and biological process using Human Protein Reference Database (HPRD; http://www.hprd.org) which is a Gene Ontology (GO) compliant database $[27,28]$. The top canonical pathways associated with the differentially expressed proteins in this study were identified through the use of QIAGEN's Ingenuity Pathway Analysis (IPA ${ }^{\circ}$, http://www.qiagen.com/ingenuity).

\section{Accessibility of proteomic data}

The data obtained in this study has been submitted to public repositories to make it accessible to the scientific community. The data on immunohistochemical analysis and the list of proteins and peptides identified has been submitted to Human Proteinpedia [28, 29] (HUPA, http://www.humanproteinpedia.org). The immunohistochemistry (IHC) can be visualised at http://www.human proteinpedia.org/Experimental_details?exp_id=TE-547399 for cholecystitis and http://www.humanproteinpedia.org/ Experimental_details?can_id $=105423$ for gallbladder adenocarcinoma. The list of proteins and peptides can be accessed at http://www.humanproteinpedia.org/data_dis play?exp_id $=00803$. The raw data has been submitted to ProteomeXchange Consortium via the PRIDE public data repository [30] and can be accessed using the data identifier - PXD001566.

\section{Immunohistochemistry}

Tissue microarrays (TMAs) were constructed at Lab Surgpath, Mumbai using the paraffin blocks of gallbladder adenocarcinoma and cholecystitis cases obtained from Cancer Hospital and Research Institute, Gwalior, India with the approval from Institutional Human Ethics Committee and informed consent of the patients. The tissue microarrays were constructed with 29 cases of gallbladder adenocarcinoma and 16 cholecystitis cases. For this, two cores of $2 \mathrm{~mm}$ size was taken from each paraffin block and embedded to a recipient paraffin block.

IHC was carried out on both cholecystitis and gallbladder adenocarcinoma cases. A semi-quantitative assessment was performed to evaluate the immunoreactivity as described previously [31]. Briefly, the formalin fixed paraffin 
embedded tissue sections were deparaffinised and antigen retrieval was carried out using heat-induced epitope retrieval by incubating the slides for 20 minutes in antigen retrieval buffer (0.01 M Trisodium citrate buffer, $\mathrm{pH}$ 6). Endogenous peroxidases were quenched using a blocking solution followed by washes with wash buffer (PBS with $0.05 \%$ Tween-20). The sections were incubated with antiMIF antibody (sc-20121, Santa Cruz Biotechnology, Dallas, TX) at 1:50 dilution overnight at $4{ }^{\circ} \mathrm{C}$ in a humidified chamber. The slides were incubated with appropriate horseradish peroxidase conjugated rabbit secondary antibody for 30 minutes at room temperature. Excess secondary antibody was removed using wash buffer followed by addition of DAB substrate. The signal was developed using DAB chromogen (DAKO, Glostrup, Denmark). Tissue sections were then observed under the microscope. The immunohistochemical labeling was assessed by an experienced pathologist. The intensity of staining was scored on a grading scale ranging from 0 to $3+$, where 0 represented negative staining, $1+$ represented weak staining, 2+ represented moderate staining and $3+$ represented strong staining. To determine the statistical significance of MIF expression in gallbladder adenocarcinoma and cholecystitis, Chi-square test was carried out using $\mathrm{R}$ version 3.1.0.

\section{Western blotting}

Whole cell extracts of GBC cells, were prepared using modified RIPA lysis Buffer (Merck Millipore, Billerica, MA) containing protease inhibitors (Roche, Indianapolis, IN) and phosphatase inhibitors (Thermo Scientific, Bremen, Germany). Rabbit polyclonal anti-MIF was obtained from Santa Cruz (sc-20121, Santa Cruz Biotechnology, Dallas, TX). $\beta$-Actin was used as a loading control. Western blot analysis was performed as previously described [32] using $30 \mu \mathrm{g}$ protein lysates.

\section{Processing of conditioned media}

Each cell line was grown to $\sim 80 \%$ confluence, washed multiple times with PBS to remove any adherent serum from the cells and then grown in serum-free medium for 8 h. Post-starvation, the conditioned media was collected for each cell line, centrifuged at $800 \times \mathrm{g}$ for $10 \mathrm{~min}$ to remove any cellular debris. The supernatant was filtered using a $0.22 \mu \mathrm{m}$ filter (Merck Millipore, Billerica, MA). The filtered supernatant was subsequently concentrated using $3 \mathrm{kDa}$ cut-off filters (Merck Millipore, Billerica, MA). Protein concentration was estimated by BCA assay [24]. Western blot analysis was performed as previously described [32] using $30 \mu \mathrm{g}$ protein lysates.

\section{Cell viability assays}

The GBC cells were seeded in a 96-well plate at a density of $1 \times 10^{4}$ cells/well. The cells were vehicle - treated or treated with MIF-antagonist [(S,R)-3-(4-hydroxyphenyl)- 4,5-dihydro-5-isoxazole acetic acid methyl ester (ISO-1) (EMD Millipore, Billerica, MA) (0 to $500 \mu \mathrm{M})$ or 4-iodo6-phenylpyrimidine (4-IPP) (Tocris Bioscience, Bristol, UK) $(0$ to $500 \mu \mathrm{M})$ for $48 \mathrm{~h}$ in complete medium at $37^{\circ} \mathrm{C}$ in $5 \% \mathrm{CO}_{2}$ incubator. After $48 \mathrm{~h}$, the medium was aspirated, the cells were rinsed and MTT assays were performed as previously described [33]. All experiments were performed in triplicate.

\section{siRNA transfection}

ON-TARGETplus SMARTpool control siRNA and MIF siRNA were purchased from Dharmacon (Lafayette, CO). The GBC cells were transfected with $10 \mathrm{nM}$ of MIF siRNA or control siRNA using RNAiMAX (Invitrogen, Carlsbad, CA) according to the manufacturer's instructions. Transfection was carried out as previously described [32]. Cells were subjected to invasion assay and viability assay $48 \mathrm{~h}$ post-transfection, unless otherwise stated.

\section{Colony formation assays}

GBC cell lines were transfected with either MIF siRNA or control siRNA. $3 \times 10^{3}$ cells/well were seeded in 6-well plates. Cell colonies were allowed to grow for 14 days, before the colonies were fixed with methanol and stained with $4 \%$ methylene blue (Sigma, St. Louis, MO). The number of colonies per dish was counted. Similarly, the colony forming ability of the GBC cells were monitored in the presence of MIF antagonists, ISO-1 and 4iodo-6-phenylpyrimidine (4-IPP). All experiments were performed in triplicate.

\section{Cell invasion assays}

Cell invasion assays were performed in a transwell system using cell culture inserts for 24-well plates with translucent polyethylene terephthalate membrane containing $8 \mu \mathrm{m}$ pores (BD Biosciences, NJ). The upper compartment of the culture insert was coated with Matrigel (BD Biosciences, San Jose, CA). GBC cells $\left(2 \times 10^{4}\right)$ were seeded into the transwell chambers in presence of serum-free medium. Complete media was added to the lower compartment and the cells were incubated at $37{ }^{\circ} \mathrm{C}$ in $5 \% \mathrm{CO}_{2}$ incubator for $48 \mathrm{~h}$. Post-incubation, the upper surface of the membrane was wiped with a cotton-tip applicator to remove non-migratory cells. Cells that migrated to the lower side of membrane were fixed and stained using $4 \%$ methylene blue (Sigma, St. Louis, MO). The number of invaded cells was counted using a light microscope. All experiments were done in duplicates and repeated thrice.

\section{Statistical analysis}

Paired t-test was carried out to evaluate the difference between control and treated groups. $P \leq 0.05$ was considered to indicate statistical significance. 


\section{Results}

Quantitative mass spectrometric analysis of GBC cell proteome

Four GBC cell lines (TGBC24TKB, OCUG-1, NOZ and GB-d1) were selected to study the GBC cell proteome based on their invasive abilities. Of the four cell lines, TGBC24TKB was non-invasive. OCUG-1, NOZ and GBd1 had varied invasive ability ranging from moderate to highly invasive (Fig. 1a). The experimental workflow used in this study is depicted in Fig. 1b. The resulting MS/MS data was searched against Human RefSeq 63 protein database using Sequest and Mascot search algorithms through Proteome Discoverer platform suite. A total of 3,653 proteins were identified. Of these, 654 proteins were found to be overexpressed ( $\geq 2$-fold) and 387 were downregulated ( $\leq 2$-fold). Among these, 31 were found to be overexpressed and 61 were found to be downregulated in all the three invasive GBC cell lines (Fig. 1c). The complete list of proteins and peptides obtained is provided in the Additional files 2 and 3. The list of the differentially expressed proteins is provided in Additional files 4 and 5.

Earlier studies in GBC have reported the dysregulation of CD44 antigen (CD44), matrix metallo peptidase 1 (MMP1) and cadherin-1 (CDH1) [34-36]. However, to our knowledge there are no reports of these proteins in high-throughput mass spectrometry data in GBC. In addition to the above mentioned molecules, this study has also identified proteins which have not been previously described in context of GBC, such as macrophage migration inhibitory factor $(M I F)$, caldesmon (CALD1), plakophilin (PKP2) and desmocollin (DSC2) however have been reported earlier in gastrointestinal cancers. A partial list of these proteins is given in Table 1.

Bioinformatics analysis of all the proteins identified in this study was carried out to categorize them based on the subcellular localization, molecular function and biological processes (Additional file $6 a, 6 b$ and $6 c$ ). The classifications were based on annotations in the Human
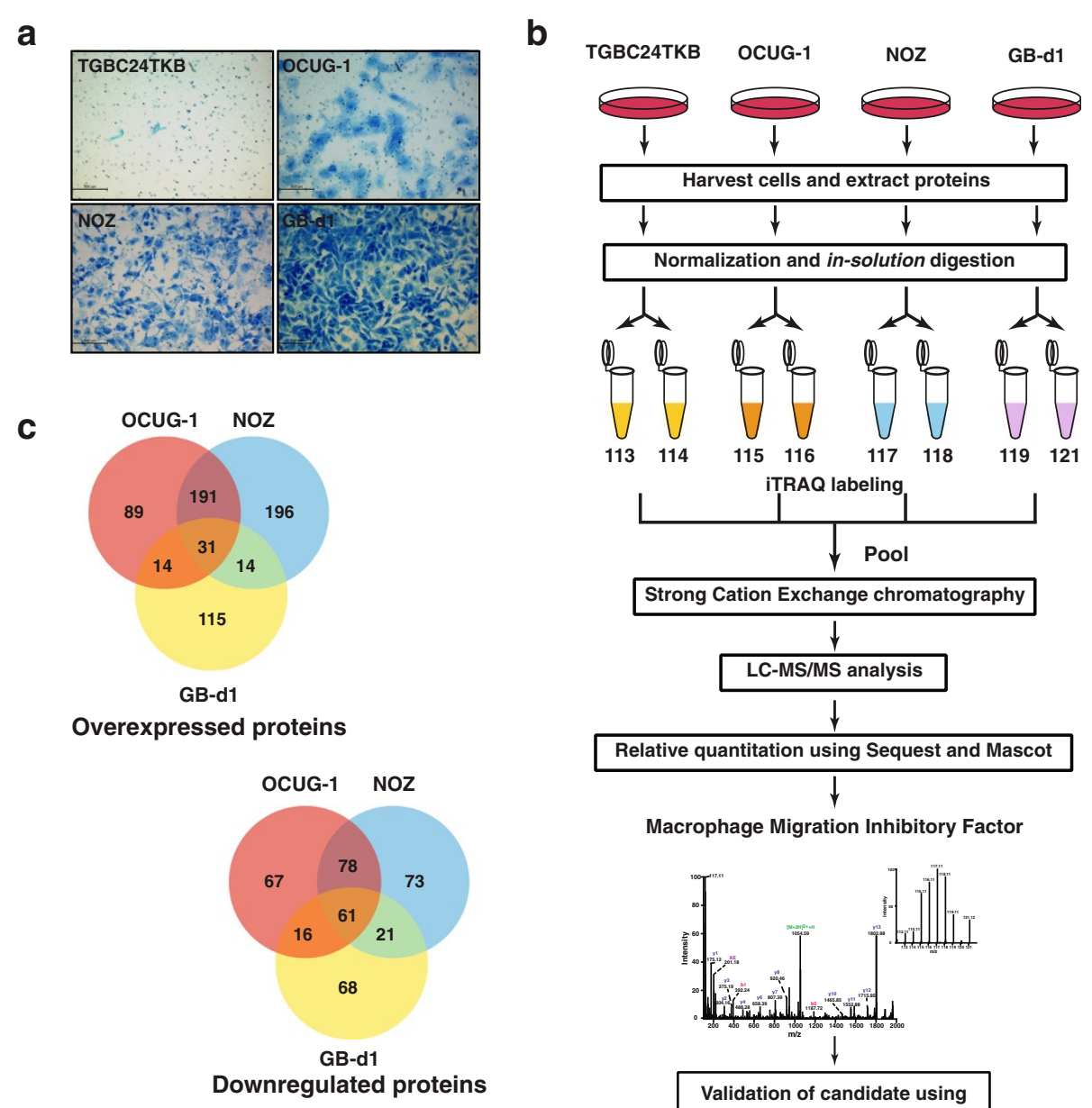

Macrophage Migration Inhibitory Factor

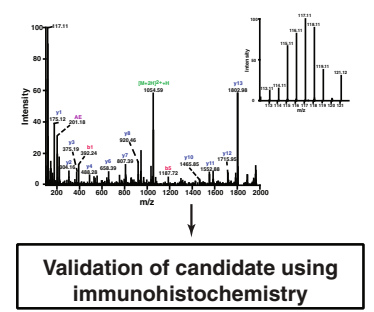

Fig. 1 Experimental design and proteomic resulta Invasive property of GBC cell lines - TGBC24TKB - non-invasive.; OCUG-1 - moderately invasive; NOZ - moderately invasive; GB-d1- highly invasive. b Workflow for quantitative proteomic analysis of GBC cell line using iTRAQ labeling. c Venn diagrams depicting the overlap of the differentially expressed proteins in the three invasive cell lines, OCUG-1, NOZ and GB-d1 
Table 1 Partial list of differentially expressed proteins identified in GBC

\begin{tabular}{|c|c|c|c|c|c|c|}
\hline \multicolumn{7}{|c|}{ Differentially expressed proteins not previously reported in GBC } \\
\hline \multirow[t]{2}{*}{ Gene symbol } & \multirow[t]{2}{*}{ Protein name } & \multirow{2}{*}{\multicolumn{2}{|c|}{ Function }} & \multicolumn{3}{|l|}{ Fold change } \\
\hline & & & & $\begin{array}{l}\text { OCUG-1/ } \\
\text { TGBC 24TKB }\end{array}$ & $\begin{array}{l}\mathrm{NOZ/TGBC} \\
24 \mathrm{TKB}\end{array}$ & $\begin{array}{l}\text { GB-d1/ TGBC } \\
24 T K B\end{array}$ \\
\hline MIF & $\begin{array}{l}\text { Macrophage migration } \\
\text { inhibitory factor }\end{array}$ & \multicolumn{2}{|l|}{ Pro-inflammatory cytokine } & 3.9 & 4.9 & 1.4 \\
\hline CALD1 & Caldesmon & \multicolumn{2}{|l|}{ Calmodulin-binding protein } & 3.6 & 1.9 & 4.2 \\
\hline DSC2 & Desmocollin-2 & \multicolumn{2}{|c|}{$\begin{array}{l}\text { Calcium-dependent glycoprotein required for cell adhesion } \\
\text { and desmosome formation }\end{array}$} & 0.2 & 0.2 & 0.3 \\
\hline PKP2 & Plakophilin-2 & \multicolumn{2}{|c|}{$\begin{array}{l}\text { Cell adhesion molecule involved in linking cadherins to } \\
\text { intermediate filaments in the cytoskeleton }\end{array}$} & 0.4 & 0.5 & 0.4 \\
\hline \multicolumn{7}{|c|}{ Differentially expressed proteins previously reported in GBC } \\
\hline \multirow[t]{2}{*}{ Gene symbol } & \multirow[t]{2}{*}{ Protein name } & \multirow[t]{2}{*}{ Function } & \multicolumn{3}{|l|}{ Fold change } & Citation \\
\hline & & & $\begin{array}{l}\text { OCUG-1/ } \\
\text { TGBC 24TKB }\end{array}$ & $\begin{array}{l}\mathrm{NOZ/TGBC} \\
24 \mathrm{TKB}\end{array}$ & $\begin{array}{l}\text { GB-d1/ } \\
\text { TGBC 24TKB }\end{array}$ & \\
\hline CD44 & CD44 antigen & $\begin{array}{l}\text { Cell-cell interactions, cell adhesion and } \\
\text { migration; cancer stem cell marker }\end{array}$ & 2.2 & 3.0 & 2.2 & $\begin{array}{l}\text { Ylagan et. al., } \\
2000 \text { [34] }\end{array}$ \\
\hline MMP1 & $\begin{array}{l}\text { Matrix metallo peptidase } \\
1\end{array}$ & Breakdown of extracellular matrix & 2.7 & 2.1 & 2.5 & $\begin{array}{l}\text { Du et. al., } \\
2011[35]\end{array}$ \\
\hline $\mathrm{CDH} 1$ & Cadherin-1 & Cell adhesion, epithelial cell marker & 0.2 & 0.3 & 0.5 & $\begin{array}{l}\text { Hirata et. al., } \\
2006[36]\end{array}$ \\
\hline
\end{tabular}

Protein Reference Database (HPRD) [27]. This analysis revealed that $27 \%$ of the proteins identified in this study localized to the nucleus and $23 \%$ localized to the cytoplasm. To gain insights into the altered pathways in GBC, network analysis was performed using the differentially expressed proteins (2-fold cut-off) in the invasive cell lines compared to the non-invasive cell line used in this study. The top canonical pathways identified using Ingenuity database are depicted under Additional file $6 \mathrm{~d}$, which includes integrin signaling and epithelial adherens junction signaling. Previous studies using mice fibroblasts indicate that cellular adhesion leads to activation of PKC resulting in the secretion of MIF. This, in turn, promotes integrin-mediated activation of MAP kinase and cell cycle progression [37].

MIF, one of the novel proteins identified by us in this study, was found to be overexpressed $>3$-fold in two of the invasive GBC cell lines and was considered for further validation. Apart from MIF, the proteins related to the MIF nexus identified in our study are depicted under Additional file 7. This signaling network of MIF and its associated molecules were identified through literature survey. Representative MS/MS spectra of a subset of peptides identified for MIF and associated molecules such as CD74 and CD44 are shown in Figs. 2a, 2b and 2c.

\section{Immunohistochemical validation of MIF in neoplastic and non-neoplastic gallbladder tissue}

Since MIF was found to be overexpressed $>3$-fold in two of the invasive GBC cell lines, we studied the expression of
MIF in primary GBC tissue using immunohistochemical staining. MIF, being a secretory molecule, shows both cytoplasmic and extracellular localization. Tissue microarray-based immunohistochemical validation was carried out using $29 \mathrm{GBC}$ and 16 cholecystitis tissues. A variable staining pattern was noted across cases of gallbladder adenocarcinoma and cholecystitis. About $72 \%$ (21 of 29) of gallbladder adenocarcinoma cases showed moderate to strong staining $(2+$ to $3+)$ while $62 \%$ (10 of 16) of the cholecystitis cases showed negative to weak staining $(0$ to $1+)$. Notably, none of the cholecystitis cases showed $3+$ staining. A Chi-square test clearly indicated a significant overexpression of MIF in gallbladder adenocarcinoma cases ( $p$-value $<0.05$ ) at a confidence level greater than $95 \%$. The results of the immunohistochemical validation are provided in Table 2. MIF was observed to be predominantly localized in the cytoplasm. The representative staining patterns for strong MIF staining (3+) in GBC and weak MIF staining (1+) in cholecystitis tissues are illustrated in Fig. 2d. The representative staining patterns for weak MIF staining (1+) in GBC and moderate MIF staining $(2+)$ in cholecystitis tissues are illustrated in Additional file 8 .

\section{MIF affects the colony forming ability of the GBC cells} Having found that MIF is overexpressed in gallbladder adenocarcinoma tissue, we sought to investigate the role of MIF in GBC. MIF has been reported to be overexpressed in multiple cancers and its role in tumor cell proliferation has been documented [17, 18, 20, 22]. We 

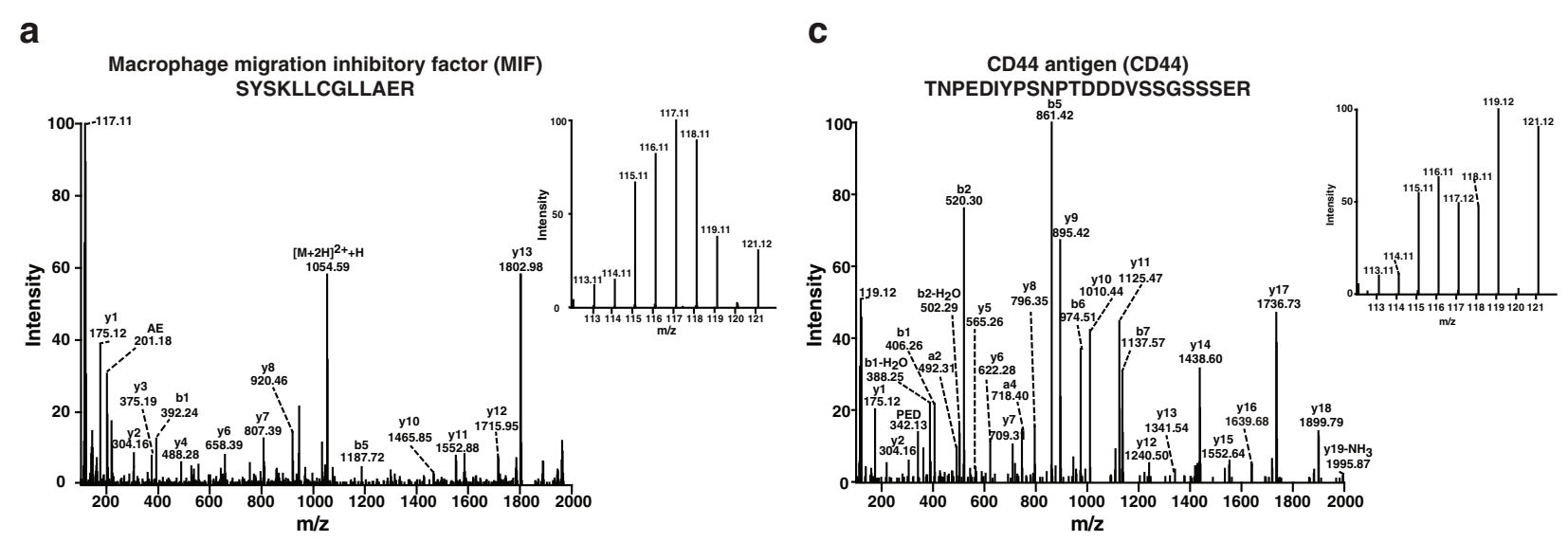

b

d
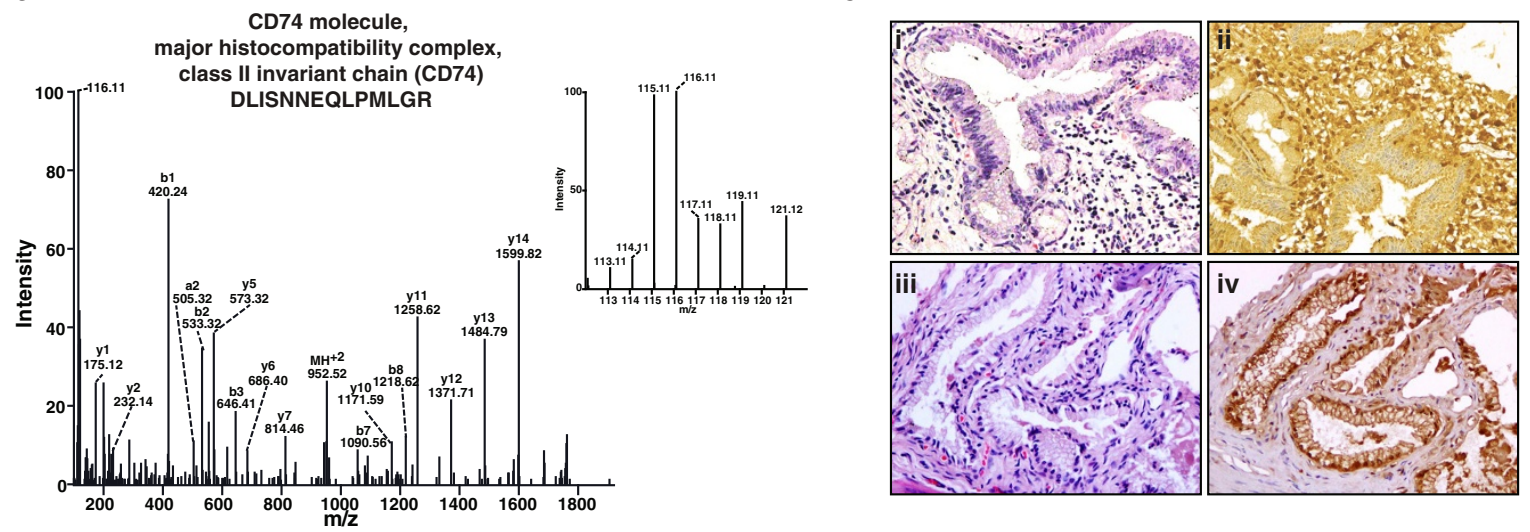

Fig. 2 Representative MS/MS spectra of overexpressed proteins and validation of MIF by immunohistochemistry. Representative MS/MS spectra of overexpressed proteins in invasive GBC cell lines, OCUG-1, NOZ and GB-d1 as compared with the non-invasive GBC cell line, TGBC24TKB. a Macrophage migration inhibitory factor (MIF). b CD74 molecule, major histocompatibility complex, class II invariant chain (CD74). c CD44 antigen (CD44). d Validation of MIF by IHC. Representative sections from cholecystitis tissues (weak staining) - (i) stained with hematoxylin and eosin; (ii) probed with anti-MIF antibody. Representative sections from gallbladder adenocarcinoma tissue (strong staining) - (iii) stained with hematoxylin and eosin; (iv) probed with anti-MIF antibody

assessed the expression of MIF in a panel of GBC cell lines (TGBC2TKB, SNU-308, G-415, TGBC24TKB, NOZ, OCUG-1 and GB-d1) and found detectable heterogeneous expression of the protein in all cell lines (Fig. 3a). The Western blot analysis of the MIF expression correlated well with the mass spectrometry results. Since MIF is a secretory protein, we checked the expression of MIF in the secretome of all the GBC cell lines

Table 2 Summary of the immunohistochemical validation for MIF in GBC

\begin{tabular}{lll}
\hline Staining Intensity & Cholecystitis & $\begin{array}{l}\text { Gallbladder } \\
\text { adenocarcinoma }\end{array}$ \\
\hline $0-1+$ (Negative - Weak) & 10 & 8 \\
$2+-3+$ (Moderate - Strong) & 6 & 21 \\
$p$-value of significance & $2.2 \mathrm{E}-02$ & \\
Subcellular location of staining & Predominantly cytoplasmic \\
\hline
\end{tabular}

(Fig. 3a). We observed a varied expression of MIF in the secretome of the six GBC cell lines. MIF was below detectable limits in the secretome of G-415. Western blot analysis revealed a significant decrease in the endogenous expression of MIF using MIF siRNA in all the cell lines (Additional file 9a).

We examined the colony formation and invasion ability of the GBC cells used in this study. As shown in Additional file 9b, all GBC cells except TGBC2TKB grow in defined colonies. The colonies of TGBC2TKB cells, that are less clearly defined than those of other GBC cells, indicate cell scattering as is evidenced by the invasion data (Additional file 9b). A comparison of the colony forming and invasive ability of the GBC cells revealed a heterogeneous pattern (Additional file 9c) with no direct association with the MIF expression. As this does not rule out the importance of MIF in the oncogenic potential of the GBC lines, we next studied the 


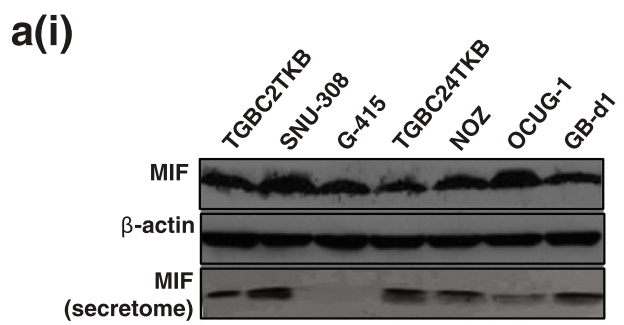

a(ii)

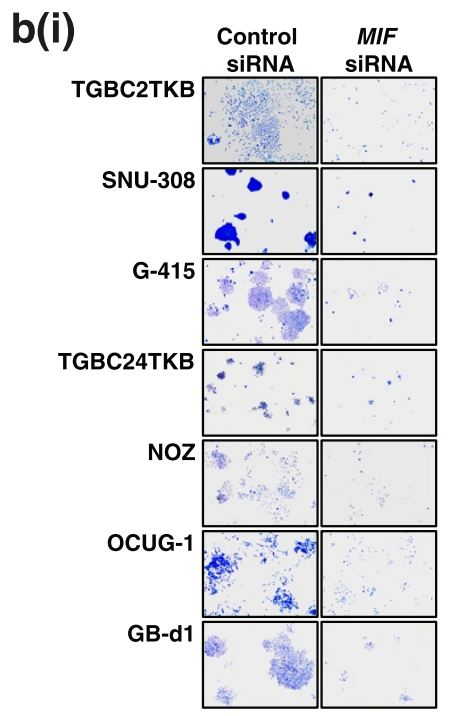

b(ii)
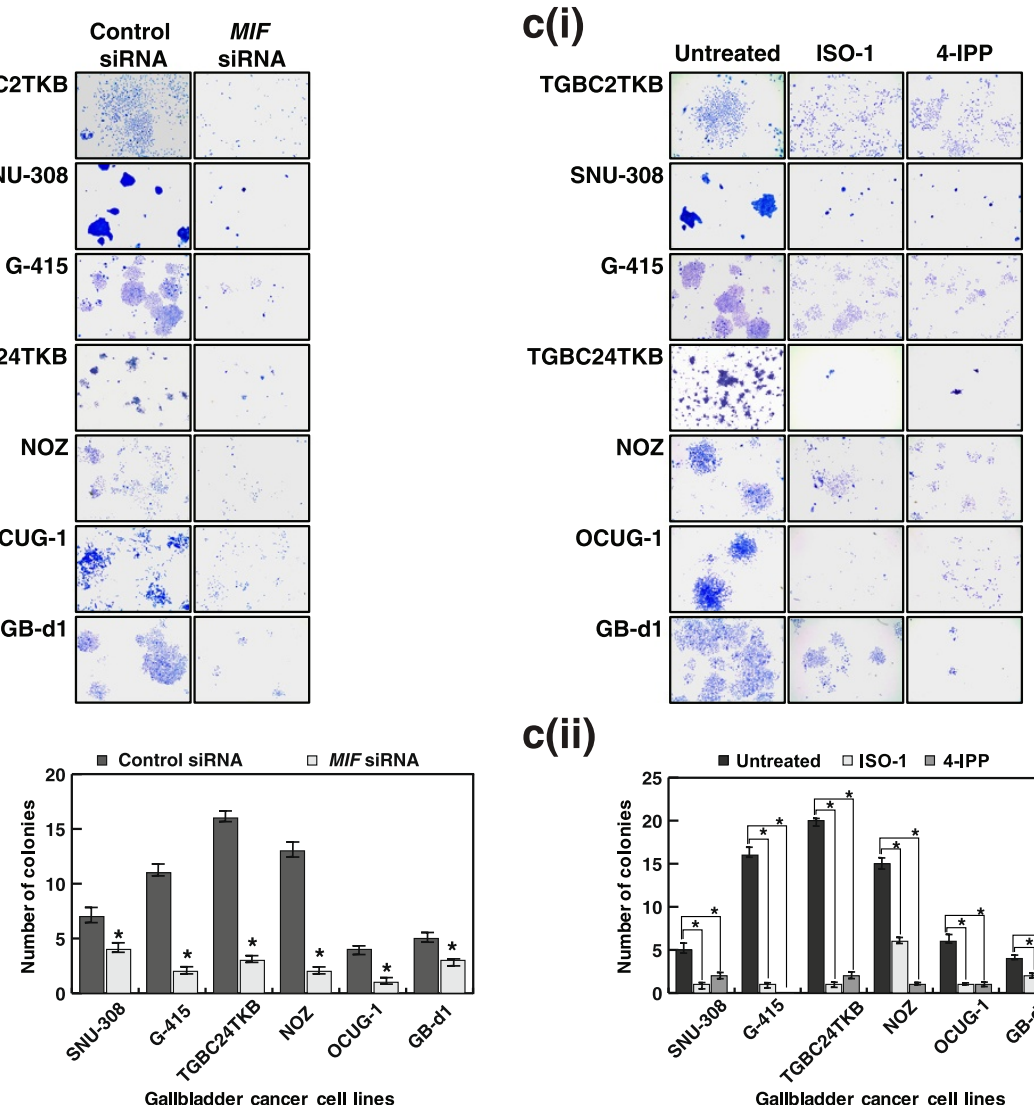

c(ii)
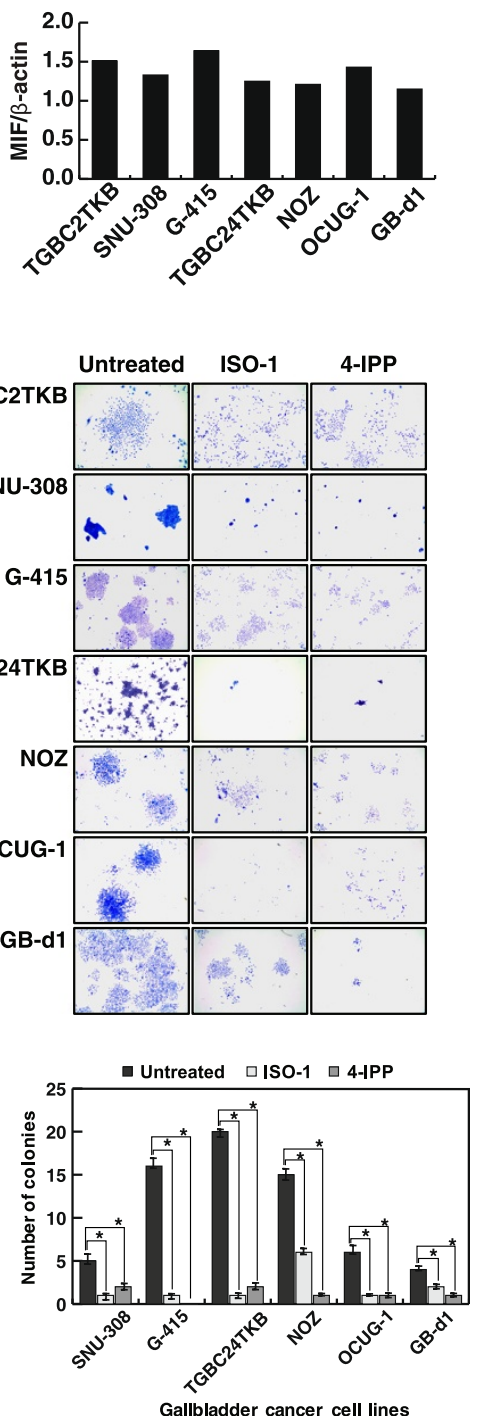

Fig. 3 MIF affects the colony forming ability of the GBC cells - a-i Expression of MIF across a panel of GBC cell lines. Western blot analysis was performed using anti-MIF antibody. $\beta$-Actin was used as loading control. Top panel: GBC whole cell lysates, Middle panel: $\beta$-Actin, Bottom panel: GBC cell secretome. a-ii A graphical representation of MIF expression in GBC cell lines compared to $\beta$-Actin. $\mathbf{b}$-i Colony forming ability of GBC cell lines was decreased post-transfection with MIF siRNA. b-ii A graphical representation of the same * $P<0.05$. c-i Inhibition of MIF in GBC cell lines with ISO-1 (50 $\mu \mathrm{M})$ and 4-IPP $(5 \mu \mathrm{M})$ led to a decrease in the colony forming ability of the cells. c-ii A graphical representation of the same ${ }^{*} P<0.05$

role of MIF in the cell survival and invasive ability of the GBC cells.

To determine whether inhibition of MIF had any effect on cell survival, we attempted to silence the expression of MIF in the GBC cell lines using MIF-specific siRNA. Colony formation assays are often carried out to analyze the ability of cells to grow infinitely contributing to its oncogenic potential. Our results indicate that siRNA-mediated silencing of $M I F$ in a panel of GBC cell lines resulted in a significant decrease in the colony forming ability of the cells ( $p$-value <0.05)
(Fig. 3b). Using an alternative strategy, GBC cell lines were treated with ISO-1, a MIF antagonist [38] and 4IPP, a MIF irreversible inhibitor [23]. GBC cell lines showed decreased cell viability in the presence of the MIF irreversible inhibitor, 4-IPP compared to the MIF antagonist ISO-1 (Additional file 10a and 10b). Akin to the effect of siRNA-mediated silencing over the colony forming ability, GBC cell lines showed a significant reduction in their colony forming ability in the presence of either $50 \mu \mathrm{M}$ ISO-1 or $5 \mu \mathrm{M}$ of 4 -IPP $(p$-value $<0.05)$ (Fig. 3c). 


\section{Inhibition of MIF decreases the invasive property of the GBC cells}

Having observed that inhibition of MIF leads to a decrease in the colony formation ability of the GBC cell lines, we addressed whether MIF has a potential role in GBC metastasis. GBC cell lines were used as an in vitro model to study their invasive property whereby the endogenous expression of MIF was silenced using its specific siRNA and its functional activity was inhibited using MIF inhibitors, ISO-1 and 4-IPP. siRNA-mediated silencing of MIF resulted in a significant decrease in the invasive ability of the cells ( $p$-value <0.05) (Fig. 4a). In agreement with the colony formation assays, treatment of GBC cell lines with $5 \mu \mathrm{M}$ of 4-IPP resulted in a significant decrease in the invasive ability of the cells ( $p$-value <0.05) (Fig. 4b). Taken together, these results indicate that 4-IPP is more potent inhibitor of MIF in GBC. These results suggest that inhibition/silencing of MIF can remarkably decrease the ability of the GBC cells to invade the extracellular matrix.

\section{Discussion}

Early diagnosis and treatment of GBC requires elucidation of molecular events associated with tumor progression and aggressiveness in GBC. Mass spectrometry has emerged as a reliable tool to identify differentially regulated proteins across different conditions enabling the discovery of potential biomarkers and therapeutic targets in cancer. In this study, quantitative proteomic analysis of a panel of $\mathrm{GBC}$ cell lines led to the identification of more than 1,000 differentially expressed proteins - 654 of which were found to be overexpressed and 387 were downregulated in invasive GBC cell lines. MIF, a proinflammatory cytokine, was found to be overexpressed $>3$ fold in two of the invasive $\mathrm{GBC}$ cell lines as compared to the non-invasive cell line, TGBC24TKB.

Tumor growth and metastasis is often accompanied by chronic inflammation, a condition commonly observed in cholecystitis and in the development of GBC. The ability of MIF to suppress anti-inflammatory pathways makes it a molecule of choice to be investigated for such

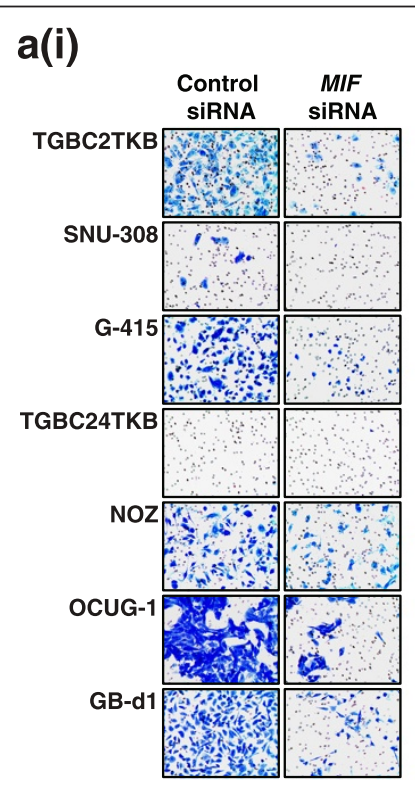

a(ii)

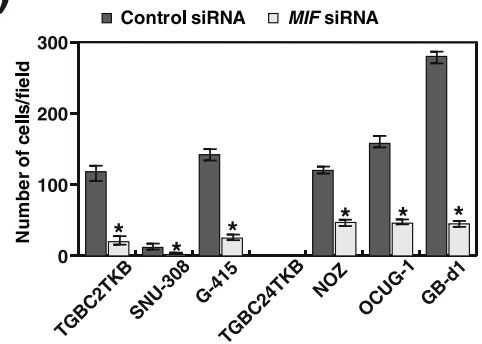

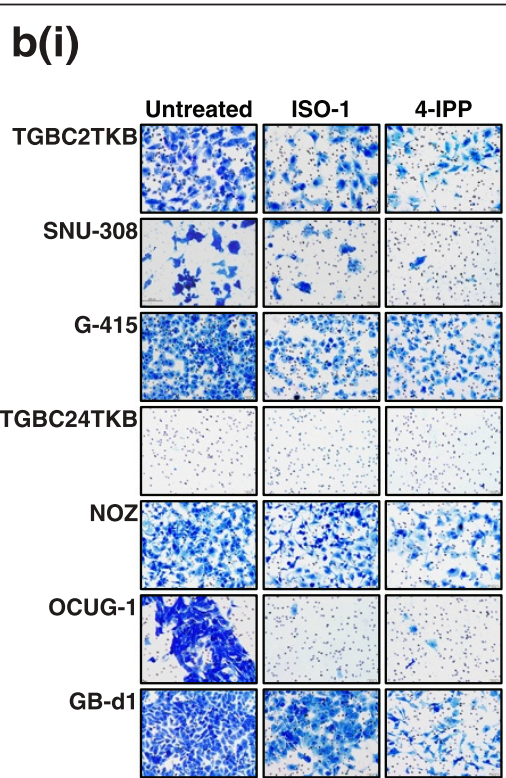

b(ii)

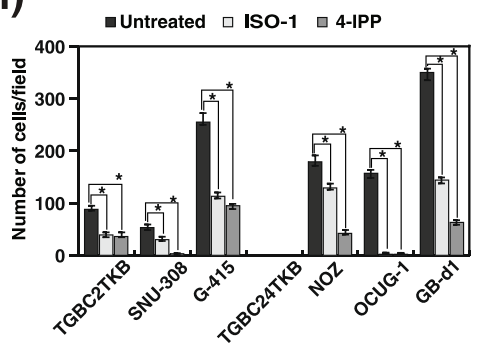

Fig. 4 Inhibition of MIF decreases the invasive property of the GBC cells. a-i siRNA mediated silencing of MIF decreases the invasive property of GBC cells. a-ii A graphical representation of the same ${ }^{*} P<0.05$. $\mathbf{b}$-i Inhibition of MIF using ISO-1 (50 $\left.\mu \mathrm{M}\right)$ and 4-IPP $(5 \mu \mathrm{M})$ lead to a decrease in the invasive ability of the GBC cells. $\mathbf{b}$-ii A graphical representation of the same ${ }^{*} P<0.05$ 
conditions. MIF enhances its activity by inducing other inflammatory cytokines including TNF-alpha and IL-1 [39]. MIF has been reported to act as an antagonist of glucocorticoids regulating its anti-inflammatory effects [15]. MIF exerts its effects via the CD74/CD44 receptor complex. MIF has also been reported to activate the chemokine receptors CXCR2 and CXCR4 [40] to exert its chemokine-like function. Overexpression of MIF has been reported in multiple human cancers $[17,18,20$, 22]. MIF contributes to tumor development, progression and tumor cell survival through inhibition of p53mediated apoptosis. This is achieved through the sustained activation of the ERK signaling pathway [41]. MIF also exerts its pro-survival and anti-apoptotic effects through the activation of PI3K/Akt cascade [42]. MIF causes an increased transcription of cyclin D leading to hyperphosphorylation of $\mathrm{Rb}$ and hence augmenting cellular proliferation [43]. Recent studies indicate that MIF leads to HIF- $1 \alpha$ activation under hypoxic conditions leading to enhancement of cancer growth and metastasis [44]. In addition, MIF has been suggested as a potential biomarker for hepatocellular carcinoma, colorectal cancer, gastric cancer and non-melanoma skin cancer [45]. CD74, which acts as a receptor to MIF, was also found to be overexpressed in two of the GBC cell lines used in the proteomic experiment in this study. The expression of CD74 has been linked to several cancers [46]. The coreceptor of MIF, CD44 was also found to be overexpressed in all the GBC cell lines. Long-term activation of CD44 has been reported to play a key role in tumor progression [34].

Studies have shown that vaccination of human subjects with autologous tumor cells modified to secrete granulocyte-macrophage colony stimulating factor (GMCSF) and antibody-based blockade of cytotoxic Tlymphocyte-associated antigen-4 (CTLA4) results in a humoral response against multiple angiogenic cytokines, including MIF. This antibody-based inhibition of MIF attenuates macrophage Tie-2 (TEK) expression and matrix metalloproteinase-9 (MMP9) production. This and studies by others indicate that blockade of VEGF, angiopoietins, and MIF may be effective in tumor regression [47, 48]. Taken together, these findings suggest that MIF can be explored as a therapeutic target in GBC.

For a molecule to act as a therapeutic target it is essential that it has to be expressed in the cancer tissue. In this study, tissue microarray-based immunohistochemical staining revealed overexpression of MIF in more than $72 \%$ of the gallbladder adenocarcinoma cases. These findings suggest MIF as a potential therapeutic target in GBC.

ISO-1 is an antagonist of MIF which binds to the hydrophobic catalytic pocket of MIF and inhibits its tautomerase activity thereby counteracting glucocorticoid- inhibited TNF release as well as inhibiting the cytokine action of MIF on PLA2 activity. Inhibition of MIF using ISO-1 has been demonstrated to provide protection from septic shock induced by endotoxins [38]. In vitro and in vivo MIF inhibition using its specific inhibitor has been shown to be potentially effective in multiple cancers $[19,23,49-54]$. In our study, knockdown of endogenous MIF expression using ISO-1 or its specific siRNA showed a significant decrease in cellular proliferation, invasion and colony forming ability of GBC cell lines. As evidenced from the current study and in agreement with literature, relatively high concentrations of ISO-1 are potentially effective in rendering cellular death. This property of ISO-1 has hindered the use of this antagonist in clinical settings. Meanwhile, the small molecule inhibitor 4-IPP has been reported to be $\sim 5-10$ times more potent than the MIF antagonist, ISO-1. The antagonist, 4-IPP acts as a suicide substrate to MIF through covalently modifying the catalytically active $\mathrm{N}$ terminal proline [23]. In this study, we demonstrate that the inhibition of MIF activity using 4-IPP decreased cellular proliferation, invasion and colony forming ability of GBC cell lines and was more potent than the prototypic MIF antagonist, ISO-1. Taken together, these studies provide experimental evidence of the potency of the MIF inhibitors in multiple cancers including GBC. We suggest that targeted MIF therapy might be effectively combined with antibody-based therapy to improve patient outcome in other cancers including GBC. Further clinical investigations of these inhibitors are needed to establish their role as a therapeutic target in cancer.

\section{Conclusions}

Our data suggests that MIF is active in GBC and plays a pivotal role in cellular proliferation and invasiveness of GBC. Our current study does not rule out the role of other molecules and/or genomic factors towards tumor progression of GBC. The findings of this study and those of others elucidates the role of MIF as a therapeutic target in multiple cancers including GBC. Further studies are warranted to confirm our findings in clinical settings.

\section{Additional files}

\section{Additional file 1: Properties of GBC cell lines used in the study.}

(XLS $27 \mathrm{~kb}$ )

Additional file 2: Proteins identified in GBC cell lines using Sequest and Mascot search algorithm. (XLS $1180 \mathrm{~kb}$ )

Additional file 3: Peptides identified in GBC cell lines using Sequest and Mascot search algorithm. (XLS $5659 \mathrm{~kb}$ )

Additional file 4: Overexpressed proteins identified in invasive GBC cell lines. (XLS $406 \mathrm{~kb}$ )

Additional file 5: Downregulated proteins identified in invasive GBC cell lines. (XLS $277 \mathrm{~kb}$ ) 
Additional file 6: Gene ontology-based classification of proteins identified in the study. (a) Subcellular localization (b) Molecular function (c) Biological process. (d) Graphical representation of the top 12 canonical pathways of the differentially expressed proteins identified in this study generated using Ingenuity Pathway Analysis. The columns represent the -log of the $p$-value for all of the genes in each particular canonical pathway family calculated based on Fisher's exact test. The line graph represents the ratio plot indicating the number of genes differentially expressed in this study relative to the total number of genes in that particular canonical pathway. (PDF $311 \mathrm{~kb}$ )

Additional file 7: A graphical representation of the proteins related to the MIF nexus identified in our study. (PDF $764 \mathrm{~kb}$ )

\section{Additional file 8: Representative images of MIF by}

immunohistochemistry. Representative sections from cholecystitis tissues (moderate staining) - (i) stained with hematoxylin and eosin; (ii) probed with anti-MIF antibody. Representative sections from gallbladder adenocarcinoma tissue (weak staining); (iii) stained with hematoxylin and eosin; (iv) probed with anti-MIF antibody. (PDF $1714 \mathrm{~kb}$ )

Additional file 9: (a) Knockdown of MIF using its specific siRNA in a panel of GBC cell lines. Western blot analysis was performed using anti-MIF antibody. $\beta$-Actin was used as a loading control. (b) Colony forming ability and invasive property of GBC cell lines. (c) Scatter plot representing invasive ability versus the colony forming ability of GBC cell lines. (PDF $1399 \mathrm{~kb}$ )

Additional file 10: Cell viability of GBC cell lines was measured by MTT assay after treatment with indicated concentrations of ISO-1 (a) and 4-IPP (b) for $48 \mathrm{~h}$. (PDF $769 \mathrm{~kb}$ )

\section{Abbreviations}

MIF: Macrophage migration inhibitory factor; iTRAQ: Isobaric tags for relative and absolute quantitation; GBC: Gallbladder cancer; ISO-1: (S, R)-3-(4hydroxyphenyl)-4,5-dihydro-5-isoxazole acetic acid methyl ester; 4-IPP: 4-iodo-6-phenylpyrimidine; IHC: Immunohistochemistry.

\section{Competing interests}

The authors declare that they have no competing interests.

\section{Authors' contributions}

$A P, H G$ and $A C$ designed the study. RG, DS and JCR provided cell lines and scientific input. TS, PLR, MAB, RR, NS and VN performed the experiments and wrote the manuscript. SR, GS, SMP and NAS performed LC-MS/MS. AHP and PG carried out data analysis. SN constructed the tissue microarrays. MAB and PKT provided the samples for immunohistochemistry. VS scored the tissue microarrays. BP and TSKP edited the manuscript. All authors have given final approval of the version to be published. All authors have read and approved the final manuscript.

\section{Acknowledgements}

We thank the Department of Biotechnology (DBT), Government of India for research support to the Institute of Bioinformatics. IOB is supported by DBT Program Support on Neuroproteomics and infrastructure for proteomic data analysis (BT/01/COE/08/05). We thank the "Infosys Foundation" for the research support to the Institute of Bioinformatics. This work was supported by the Science and Engineering Research Board, Department of Science and Technology, Government of India grant "miRNAs in chronic tobacco-induced oral cancer (SR/SO/HS-02081/2012)"; NCl's Clinical Proteomic Tumor Analysis Consortium initiative (U24CA160036) and FAMRI-funded 072017 YCSA. P.K. Tiwari acknowledges research support from the Indian Council of Medical Research (ICMR) and DBT, Government of India. Harsha Gowda is a Wellcome Trust/DBT India Alliance Early Career Fellow. Juan Carlos Roa acknowledges research support from the National Fund for Scientific and Technological Development (FONDECYT 1130204), and CONICYT- FONDAP 15130011, Government of Chile. Pamela Leal acknowledges research support from the National Fund for Scientific and Technological Development (FONDECYT 1151008) and Postdoc Research Fellowship (CONICYT-BECAS CHILE 74130044), Government of Chile. Mustafa A. Barbhuiya is a recipient of Senior Research Fellowship from ICMR, India. Gajanan Sathe is a recipient of Senior Research Fellowship from the Council for Scientific and Industrial Research (CSIR), India. Remya Raja is a recipient of Research Associateship from DBT,
Government of India. Santosh Renuse and Nazia Syed are recipients of Senior Research Fellowship from University Grants Commission (UGC), Government of India. We thank Dr. S. K. Shankar of National Institute of Mental Health and Neuro Sciences for providing the use microscope facility.

\section{Author details}

${ }^{1}$ Institute of Bioinformatics, International Technology Park, Bangalore 560066, India. ${ }^{2}$ Amrita School of Biotechnology, Amrita University, Kollam 690525, India. ${ }^{3}$ Department of Pathology, Center of Genetic and Immunological Studies (CEGIN) and Scientific and Technological Bioresource Nucleus (BIOREN), Universidad de La Frontera, Temuco, Chile. ${ }^{4}$ McKusick-Nathans Institute of Genetic Medicine, Johns Hopkins University School of Medicine, Baltimore, MD 21205, USA. ${ }^{5}$ Adrienne Helis Malvin Research Foundation, New Orleans, LA 70130, USA. ${ }^{6}$ Manipal University, Madhav Nagar, Manipal 576104, India. ${ }^{7}$ YU-IOB Center for Systems Biology and Molecular Medicine, Yenepoya University, Mangalore 575018, India. ${ }^{8}$ Department of Biochemistry and Molecular Biology, School of Life Sciences, Pondicherry University, Puducherry 605014, India. ${ }^{9}$ School of Biotechnology, KIIT University, Bhubaneswar, Odisha 751024, India. ${ }^{10}$ Department of Pathology, Advanced Center for Chronic Diseases (ACCDiS), CITO, Pontificia Universidad Católica de Chile, Santiago, Chile. ${ }^{11}$ Department of Otolaryngology-Head and Neck Surgery, Johns Hopkins University School of Medicine, Baltimore, MD 21231, USA. ${ }^{12}$ Lab Surgpath, Mumbai 400034, India. ${ }^{13}$ Centre for Genomics, Molecular and Human Genetics, Jiwaji University, Gwalior 474011, India. ${ }^{14}$ School of Studies in Zoology, Jiwaji University, Gwalior, India. ${ }^{15}$ Department of Pathology, National Institute of Mental Health and Neurosciences, Bangalore 560029, India. ${ }^{16}$ NIMHANS-IOB Proteomics and Bioinformatics Laboratory, Neurobiology Research Centre, National Institute of Mental Health and Neurosciences, Bangalore 560029, India. ${ }^{17}$ Departments of Biological Chemistry, Johns Hopkins University School of Medicine, Baltimore, MD 21205, USA. ${ }^{18}$ Departments of Oncology, Johns Hopkins University School of Medicine, Baltimore, MD 21205, USA. ${ }^{19}$ Departments of Pathology, Johns Hopkins University School of Medicine, Baltimore, MD 21205, USA.

Received: 18 February 2015 Accepted: 27 October 2015 Published online: 04 November 2015

\section{References}

1. Misra S, Chaturvedi A, Misra NC, Sharma ID. Carcinoma of the gallbladder. Lancet Oncol. 2003;4:167-76.

2. Lazcano-Ponce EC, Miquel JF, Munoz N, Herrero R, Ferrecio C, Wistuba II, et al. Epidemiology and molecular pathology of gallbladder cancer. CA Cancer J Clin. 2001;51:349-64.

3. Rupesh P, Manoj P, Vijay Kumar S. Biomarkers in carcinoma of the gallbladder. Expert Opin Med Diagn. 2008;2:511-26.

4. Faris JE, Zhu AX. Targeted therapy for biliary tract cancers. J Hepatobiliary Pancreat Sci. 2012;19:326-36.

5. Zhang LQ, Zhang XD, Xu J, Wan Y, Qu K, Zhang JY, et al. Potential therapeutic targets for the primary gallbladder carcinoma: estrogen receptors. Asian Pac J Cancer Prev. 2013;14:2185-90.

6. Matsushita S, Onishi H, Nakano K, Nagamatsu I, Imaizumi A, Hattori M, et al. Hedgehog signaling pathway is a potential therapeutic target for gallbladder cancer. Cancer Sci. 2014;105:272-80.

7. Leal P, Garcia P, Sandoval A, Buchegger K, Weber H, Tapia O, et al. AKT/ mTOR substrate P70S6K is frequently phosphorylated in gallbladder cancer tissue and cell lines. Onco Targets Ther. 2013;6:1373-84.

8. Pawar H, Kashyap MK, Sahasrabuddhe NA, Renuse S, Harsha HC, Kumar P, et al. Quantitative tissue proteomics of esophageal squamous cell carcinoma for novel biomarker discovery. Cancer Biol Ther. 2011;12:510-22.

9. Chaerkady R, Harsha HC, Nalli A, Gucek M, Vivekanandan P, Akhtar J, et al. A quantitative proteomic approach for identification of potential biomarkers in hepatocellular carcinoma. J Proteome Res. 2008;7:4289-98.

10. Syed N, Chavan S, Sahasrabuddhe NA, Renuse S, Sathe G, Nanjappa V, et al. Silencing of high-mobility group box 2 (HMGB2) modulates cisplatin and 5fluorouracil sensitivity in head and neck squamous cell carcinoma. Proteomics. 2015;15:383-93.

11. Wang W, Ai KX, Yuan Z, Huang XY, Zhang HZ. Different expression of S100A8 in malignant and benign gallbladder diseases. Dig Dis Sci. 2013:58:150-62.

12. Tan Y, Ma SY, Wang FQ, Meng HP, Mei C, Liu A, et al. Proteomic-based analysis for identification of potential serum biomarkers in gallbladder cancer. Oncol Rep. 2011;26:853-9. 
13. Wang JW, Peng SY, Li JT, Wang Y, Zhang ZP, Cheng Y, et al. Identification of metastasis-associated proteins involved in gallbladder carcinoma metastasis by proteomic analysis and functional exploration of chloride intracellular channel 1. Cancer Lett. 2009;281:71-81.

14. Dong P, He XW, Gu J, Wu WG, Li ML, Yang JH, et al. Vimentin significantly promoted gallbladder carcinoma metastasis. Chin Med J (Engl). 2011;124:4236-44.

15. Calandra T, Roger T. Macrophage migration inhibitory factor: a regulator of innate immunity. Nat Rev Immunol. 2003;3:791-800.

16. He XX, Yang J, Ding YW, Liu W, Shen QY, Xia HH. Increased epithelial and serum expression of macrophage migration inhibitory factor (MIF) in gastric cancer: potential role of MIF in gastric carcinogenesis. Gut. 2006;55:797-802.

17. Kindt N, Laurent G, Nonclercq D, Journe F, Ghanem G, Duvillier H, et al. Pharmacological inhibition of macrophage migration inhibitory factor interferes with the proliferation and invasiveness of squamous carcinoma cells. Int J Oncol. 2013;43:185-93.

18. Zhang L, Ye SB, Ma G, Tang XF, Chen SP, He J, et al. The expressions of MIF and CXCR4 protein in tumor microenvironment are adverse prognostic factors in patients with esophageal squamous cell carcinoma. J Transl Med. 2013;11:60.

19. He XX, Chen K, Yang J, Li XY, Gan HY, Liu CY, et al. Macrophage migration inhibitory factor promotes colorectal cancer. Mol Med. 2009;15:1-10.

20. Funamizu N, Hu C, Lacy C, Schetter A, Zhang G, He P, et al. Macrophage migration inhibitory factor induces epithelial to mesenchymal transition, enhances tumor aggressiveness and predicts clinical outcome in resected pancreatic ductal adenocarcinoma. Int J Cancer. 2013;132:785-94.

21. Hagemann T, Robinson SC, Thompson RG, Charles K, Kulbe H, Balkwill FR. Ovarian cancer cell-derived migration inhibitory factor enhances tumor growth, progression, and angiogenesis. Mol Cancer Ther. 2007;6:1993-2002.

22. Meyer-Siegler KL, Vera PL, Iczkowski KA, Bifulco C, Lee A, Gregersen PK, et al. Macrophage migration inhibitory factor (MIF) gene polymorphisms are associated with increased prostate cancer incidence. Genes Immun. 2007;8:646-52.

23. Winner M, Meier J, Zierow S, Rendon BE, Crichlow GV, Riggs R, et al. A novel, macrophage migration inhibitory factor suicide substrate inhibits motility and growth of lung cancer cells. Cancer Res. 2008:68:7253-7.

24. Smith PK, Krohn RI, Hermanson GT, Mallia AK, Gartner FH, Provenzano MD, et al. Measurement of protein using bicinchoninic acid. Anal Biochem. 1985;150:76-85.

25. Chaerkady R, Kerr CL, Marimuthu A, Kelkar DS, Kashyap MK, Gucek M, et al. Temporal analysis of neural differentiation using quantitative proteomics. J Proteome Res. 2009;8:1315-26.

26. Olsen JV, de Godoy LM, Li G, Macek B, Mortensen P, Pesch R, et al. Parts per million mass accuracy on an Orbitrap mass spectrometer via lock mass injection into a C-trap. Mol Cell Proteomics. 2005;4:2010-21.

27. Goel R, Harsha HC, Pandey A, Prasad TSK. Human Protein Reference Database and Human Proteinpedia as resources for phosphoproteome analysis. Mol Biosyst. 2012;8:453-63.

28. Muthusamy B, Thomas JK, Prasad TSK, Pandey A. Access guide to human proteinpedia. In: Baxevanis AD, editor. Current Protocols in Bioinformatics, vol. Chapter 1. 2013. p. Unit 121.

29. Kandasamy K, Keerthikumar S, Goel R, Mathivanan S, Patankar N, Shafreen B, et al. Human Proteinpedia: a unified discovery resource for proteomics research. Nucleic Acids Res. 2009;37:D773-781.

30. Vizcaino JA, Cote RG, Csordas A, Dianes JA, Fabregat A, Foster JM, et al. The PRoteomics IDEntifications (PRIDE) database and associated tools: status in 2013. Nucleic Acids Res. 2013;41:D1063-1069.

31. Sahasrabuddhe NA, Barbhuiya MA, Bhunia S, Subbannayya T, Gowda H, Advani J, et al. Identification of prosaposin and transgelin as potential biomarkers for gallbladder cancer using quantitative proteomics. Biochem Biophys Res Commun. 2014;446:863-9.

32. Chang X, Ravi R, Pham V, Bedi A, Chatterjee A, Sidransky D. Adenylate kinase 3 sensitizes cells to cigarette smoke condensate vapor induced cisplatin resistance. PLoS One. 2011;6, e20806.

33. Chatterjee A, Mambo E, Zhang Y, Deweese T, Sidransky D. Targeting of mutant hogg1 in mammalian mitochondria and nucleus: effect on cellular survival upon oxidative stress. BMC cancer. 2006;6:235.

34. Ylagan LR, Scholes J, Demopoulos R. Cd44: a marker of squamous differentiation in adenosquamous neoplasms. Arch Pathol Lab Med. 2000;124:212-5
35. Du X, Wang S, Lu J, Cao Y, Song N, Yang T, et al. Correlation between MMP1-PAR1 axis and clinical outcome of primary gallbladder carcinoma. Jpn J Clin Oncol. 2011;41:1086-93.

36. Hirata K, Ajiki T, Okazaki T, Horiuchi H, Fujita T, Kuroda Y. Frequent occurrence of abnormal E-cadherin/beta-catenin protein expression in advanced gallbladder cancers and its association with decreased apoptosis. Oncology. 2006;71:102-10.

37. Liao H, Bucala R, Mitchell RA. Adhesion-dependent signaling by macrophage migration inhibitory factor (MIF). J Biol Chem. 2003;278:76-81.

38. Al-Abed $Y$, Dabideen D, Aljabari B, Valster A, Messmer D, Ochani M, et al. ISO-1 binding to the tautomerase active site of MIF inhibits its proinflammatory activity and increases survival in severe sepsis. J Biol Chem. 2005:280:36541-4.

39. Candido J, Hagemann T. Cancer-related inflammation. J Clin Immunol. 2013;33 Suppl 1:S79-84.

40. Bernhagen J, Krohn R, Lue H, Gregory JL, Zernecke A, Koenen RR, et al. MIF is a noncognate ligand of CXC chemokine receptors in inflammatory and atherogenic cell recruitment. Nat Med. 2007;13:587-96.

41. Hudson JD, Shoaibi MA, Maestro R, Carnero A, Hannon GJ, Beach DH. A proinflammatory cytokine inhibits p53 tumor suppressor activity. J Exp Med. 1999:190:1375-82.

42. Lue H, Thiele M, Franz J, Dahl E, Speckgens S, Leng L, et al. Macrophage migration inhibitory factor (MIF) promotes cell survival by activation of the Akt pathway and role for CSN5/JAB1 in the control of autocrine MIF activity. Oncogene. 2007;26:5046-59.

43. Petrenko O, Moll UM. Macrophage migration inhibitory factor MIF interferes with the Rb-E2F pathway. Mol Cell. 2005;17:225-36.

44. Winner M, Koong AC, Rendon BE, Zundel W, Mitchell RA. Amplification of tumor hypoxic responses by macrophage migration inhibitory factordependent hypoxia-inducible factor stabilization. Cancer Res. 2007;67:186-93.

45. Grieb G, Merk M, Bernhagen J, Bucala R. Macrophage migration inhibitory factor (MIF): a promising biomarker. Drug News Perspect. 2010;23:257-64.

46. Borghese F, Clanchy FI. CD74: an emerging opportunity as a therapeutic target in cancer and autoimmune disease. Expert Opin Ther Targets. 2011;15:237-51.

47. Schoenfeld J, Jinushi M, Nakazaki Y, Wiener D, Park J, Soiffer R, et al. Active immunotherapy induces antibody responses that target tumor angiogenesis. Cancer Res. 2010;70:10150-60.

48. Rabinovich GA, Gabrilovich D, Sotomayor EM. Immunosuppressive strategies that are mediated by tumor cells. Annu Rev Immunol. 2007;25:267-96.

49. Dessein AF, Stechly L, Jonckheere N, Dumont P, Monte D, Leteurtre $E$, et al Autocrine induction of invasive and metastatic phenotypes by the MIFCXCR4 axis in drug-resistant human colon cancer cells. Cancer Res. 2010:70:4644-54.

50. Meyer-Siegler KL, Iczkowski KA, Leng L, Bucala R, Vera PL. Inhibition of macrophage migration inhibitory factor or its receptor (CD74) attenuates growth and invasion of DU-145 prostate cancer cells. J Immunol. 2006:177:8730-9.

51. Du W, Wright BM, Li X, Finke J, Rini Bl, Zhou M, et al. Tumor-derived macrophage migration inhibitory factor promotes an autocrine loop that enhances renal cell carcinoma. Oncogene. 2013;32:1469-74.

52. Piette C, Deprez M, Roger T, Noel A, Foidart JM, Munaut C. The dexamethasone-induced inhibition of proliferation, migration, and invasion in glioma cell lines is antagonized by macrophage migration inhibitory factor (MIF) and can be enhanced by specific MIF inhibitors. J Biol Chem. 2009;284:32483-92

53. Baron N, Deuster O, Noelker C, Stuer C, Strik H, Schaller C, et al. Role of macrophage migration inhibitory factor in primary glioblastoma multiforme cells. J Neurosci Res. 2011;89:711-7.

54. Liu H, Chen G, Zhang W, Zhu JY, Lin ZQ, Gong ZC, et al. Overexpression of macrophage migration inhibitory factor in adenoid cystic carcinoma: correlation with enhanced metastatic potential. J Cancer Res Clin Oncol. 2013;139:287-95. 